\title{
Computer-Assisted Flicker Analysis of Rembrandt Print States
}

\author{
Robert Haas \\ Cleveland Heights, OH, USA \\ Email: rhaas3141@yahoo.com
}

How to cite this paper: Haas, R. (2018). Computer-Assisted Flicker Analysis of Rembrandt Print States. Creative Education, 9, 1648-1653.

https://doi.org/10.4236/ce.2018.911119

Received: March 20, 2018

Accepted: August 28, 2018

Published: August 31, 2018

Copyright $\odot 2018$ by author and Scientific Research Publishing Inc. This work is licensed under the Creative Commons Attribution International License (CC BY 4.0).

http://creativecommons.org/licenses/by/4.0/

\begin{abstract}
Viewing rapidly alternating aligned computer images permits easy identification of changes between two print states. Three Rembrandt print examples are presented; a general characteristic (increasing darkness) is noted; and a potential application for this new method (classification in an Internet-based worldwide print database) is discussed.
\end{abstract}

\section{Keywords \\ Computer-Assisted Analysis, Print States}

\section{Introduction}

A fascinating characteristic of the print medium is that, in looking from one print state to the next, one sees a developing art object (unlike other media, like paintings or drawings that yield only a single, final, object). But to see the development one must accurately note every change between the two states, a task that, for a large complicated print, can be challenging, or at least time-consuming. The present study describes a simple new method, using computer assistance, that makes the analysis almost effortless: One sends the aligned scanned images to a display screen alternating in rapid succession several times per second. Portions unchanged between the two states blend into one steady image; but changed areas flicker, and draw instant attention. ${ }^{1}$

${ }^{1}$ I first learned the idea of flicker analysis from the 1950s work of the Shakespeare scholar Charlton Hinman, who built an optomechanical device to similarly find damaged letters in printed copies of the Shakespeare First Folio (Hinman, 1955). Following these letters around in subsequent pages and works revolutionized the understanding of Shakespeare-era printing practice (Hinman, 1963). Hinman himself mentioned that his machine could also be used to compare states of prints or engravings (Hinman, 1955: pp. 133, 134). 


\section{Method}

Jared Bendis (Creative New Media Officer for Digital Learning and Scholarship at Case Western Reserve University) scanned Rembrandt print images (White, 1969) into .pdf computer files using an Epson Expression 10000 XL scanner, then superimposed pairs from different states as layers in the program Photoshop. The two images in each pair were aligned, setting the opacity of the top layer to $50 \%$ and (for portraits) aiming to superimpose the eyes, then animated to alternate several times per second. He then put the flickering pairs corresponding to Figures 1-3 below into a website at https://rhaas3141.wordpress.com.

\section{Results}

Figures 1-3 (when viewed in the website) show flickering images of Rembrandt's prints, respectively, of The Shell (states I and II; White plates 252 and 253), Self-portrait drawing at a Window (states I and II; White plates 184 and 185), and Clement de Jonghe (states I and V; White plates 188 and 189) (https://rhaas3141.wordpress.com).

The flicker analysis of the celebrated shell print, Figure 1, shows how Rembrandt has carried the shell, shadow, and artist's signature from state I to II
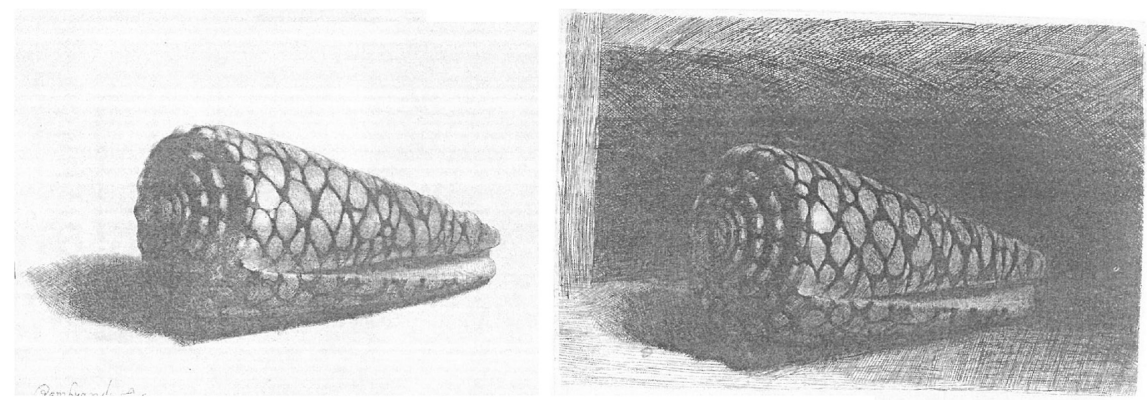

Figure 1. The Shell (states I and II).
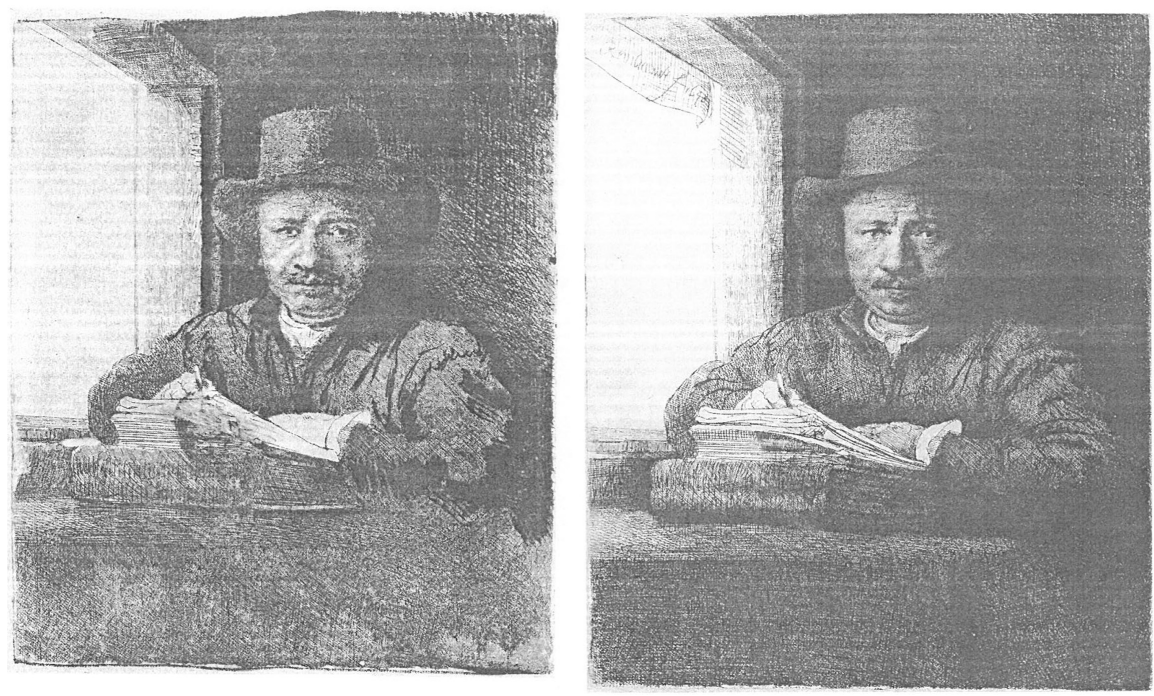

Figure 2. Self-portrait drawing at a Window (states I and II). 

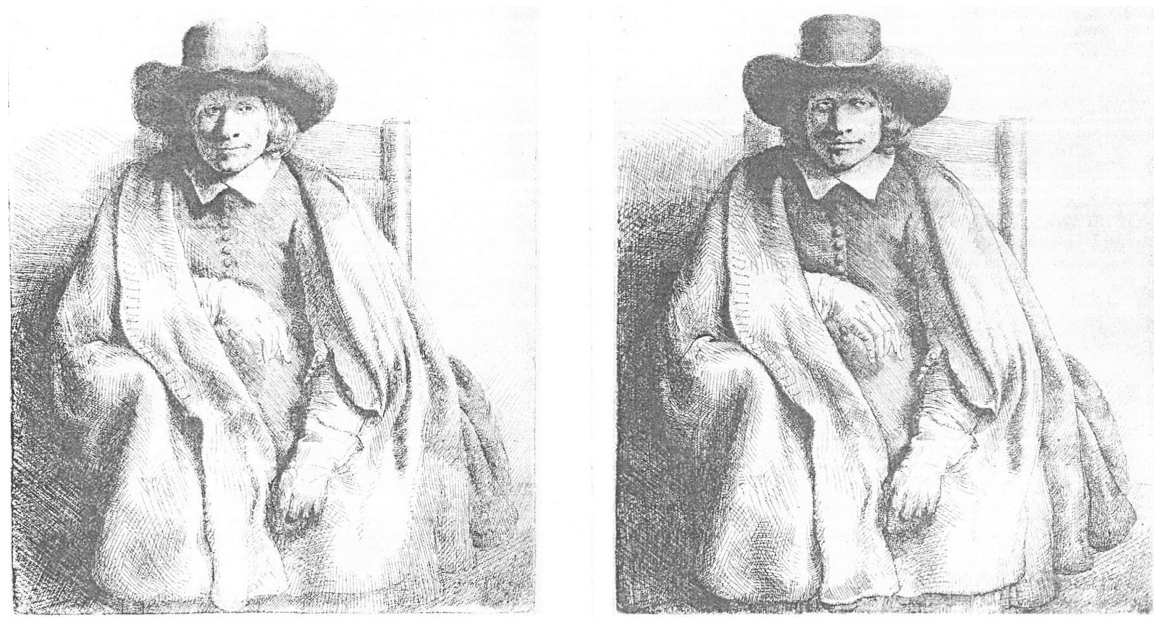

Figure 3. Clement de Jonghe (states I and V).

almost unchanged, creating the considerably different effect of state II mainly by adding the heavy dark background. The two prints do not align perfectly, the shell in state II being tipped down (clockwise) a few degrees relative to state I. But this does no harm, as the observer can compensate and read the analysis easily enough. Rembrandt has utilized variation in both the plate and the inking. In state II many of the light polygons of the shell have been somewhat darkened, and-easy to overlook in the isolated prints, but highlighted through the flickering-four of the smallest polygons, near and above the midline, are missing completely.

In the self-portrait, Figure 2, flicker analysis helps identify the numerous changes Rembrandt has made in going to the second state that he considered finished enough to add his signature at the top left: Brightening the window, while darkening the background and the tablecloth and suppressing its pattern; diminishing the white shirt collar and darkening the left hand; darkening the coat, thus toning down or suppressing its dark creases and the rent in the left sleeve, while making the whole body come forward a bit; darkening the hat and widening its brim; deepening the shadow on the right side of the face, and moving the crease between the eyes more toward the center; while leaving the eyes, all-penetrating from the start, unchanged.

Some similar changes occur in Rembrandt's print portrait of his friend or admirer, the printseller Clement de Jonghe; Figure 3 examines what changes have accumulated through all five states by a flicker analysis comparison of states I and V. Here for framing purposes Rembrandt added a faint upper background arch, and also narrowed the upper chair rung behind the sitter's head. He sharpened the outline of the entire figure by deepening the shadow at the left, and also sharpening and darkening the lower right edge and folds of the cloak. For similar reasons he also darkened the doublet, the fingers of the right hand, and the shadows on the right cheek and the left mass of hair. Perhaps most dramatic is the broad-brimmed Dutch hat. The flicker analysis clearly shows how strong an effect Rembrandt's minute adjustments-darkening the crown, and giving 
the brim an uninterrupted sweep around the left side and across the front-have in making the sitter appear a powerful and important person.

\section{Discussion}

This article has introduced a new method, computer-assisted flicker analysis, for making the changes between two print states readily visible, and has demonstrated it on Rembrandt prints of a shell, a self-portrait, and a portrait (Figures 1-3). These show with what artistry Rembrandt used quite small changes-omitting a few polygons in the shell pattern, moving the forehead crease between the eyes in the self-portrait, and adjusting the sweep of the hat in the portrait-to achieve his desired effects.

Flicker analysis notably marries strengths of the machine and the human user. People do not minutely compare separate pictures well, a task seldom needed in the real world, and wearisome and error-prone to do. But sending alternating images to the screen is trivial for a computer, and the resulting flicker display converts any differences into motion, which the human visual system is optimized to detect: A person exists today because all his human and pre-human ancestors noticed all approaching predators soon enough to escape being eaten, as well as enough prey to avoid starvation themselves. So human vision is "hard-wired" to detect motion like that of the flicker display instantly and effortlessly.

Human vision is also robust: evolved in a world filled with shifting shadows and quivering leaves, it has no difficulty from minor misalignments of the flicker images. In contrast the computer, if it made a mechanical pixel-by-pixel comparison, would be hopelessly misled by the slightest misalignment.

Flicker analysis will, it is hoped, provide a useful new tool to study the prints of Rembrandt and other artists. It squarely targets the unique characteristic of prints, mentioned in the introduction, to show a developing art object. For the present initial study I concentrate on one evident result: Rembrandt liked dark pictures. His many dark late paintings already suggest it; but the conclusion is compromised there by the concurrent centuries-long accumulation of grime, darkening layers of varnish, and possible changes in pigments. Prints provide a far clearer proof: In all three prints studied here by flicker analysis, Rembrandt's answer to "How can I improve this in the next state?" was "Make it darker".

This action is entirely consistent with Rembrandt's artistic personality, which strove unceasingly for meaning and depth. For, scientifically speaking, until fully half the pixels in an image are black, adding more black ones increases its information content. ${ }^{3}$ In an image filled with dark shadows one can (and Rembrandt

${ }^{2}$ In the self-portrait, Figure 2, Rembrandt made the darks darker and the light window lighter, so increasing the total dynamic range (see discussion below).

${ }^{3}$ A totally white scene holds only a single piece of information. If one of $\mathrm{n}$ pixels is black, there are $\mathrm{n}$ possible choices for its location. For two black pixels, there are $n(n-1) / 2$ possibilities. In general, for $\mathrm{m}$ black pixels there are $\mathrm{C}(\mathrm{n}, \mathrm{m})=\mathrm{n} ! /[\mathrm{m} !(\mathrm{n}-\mathrm{m}) !]$ possibilities (i.e., by the binomial theorem, the coefficient of $x^{m}$ in the expansion of $\left.(x+y)^{n}\right) . C(n, m)$ - as one may show by calculating the ratio $\mathrm{C}(\mathrm{n}, \mathrm{m}+1) / \mathrm{C}(\mathrm{n}, \mathrm{m})=(\mathrm{n}-\mathrm{m}) /(\mathrm{m}+1)$-increases with $\mathrm{m}$ until $\mathrm{m}=\mathrm{n} / 2$ (for $\mathrm{n}$ even), or $\mathrm{m}=(\mathrm{n}-$ 1)/2 (for $n$ odd). 
did) say more. But in our faster-paced modern life the darker print may seem irritatingly dark and murky, while the earlier state, rendering up its (lesser) meaning more easily, may appear more open, clear, and beautiful.

Rembrandt's time and location may also be factors. The Netherlands are a dark northern country with 200 days of rain or fog per year (Netherlands, 1953). People can function perfectly well in subdued light, because the eye has immense powers of accommodation, becoming-e.g. after one has sat in a darkened movie theater for half an hour-thousands of times more sensitive (Buser \& Imbert, 1992; Davson, 1990). In Rembrandt's time anyone needing more light simply sat by a window (as in Figure 2) or in a doorway (suggested by the arch in Figure 3). It probably also helped to shield one's sensitive dark-adapted eyes from overhead sky glare with a wide-brimmed black hat worn even indoors, as in both Figure 2 and Figure 3. People seem to have been accustomed to a far greater "dynamic range" of illumination than today, in particular, to far deeper darks. This is shown by a then popular genre of painting, the Caravaggiesque scene dramatically lit by a single candle. ${ }^{4}$ Its illumination spans the full range, from impenetrable black at the periphery to dazzling pure white at the light source. But we today have never regarded the world for long with dark-adapted eyes, or experienced a scene lit by a single candle, because electric lighting bleaches our world to the bright edge of the range: a single 100-watt bulb puts out 1690 lumens, over 130 candles of illumination. So the times have, to a degree, moved Rembrandt's prints, and his artistic choices in making them, beyond our experience or possibility of full appreciation.

Rembrandt prints are precious and fragile, and there has been a natural tendency for museums and other owners to hide them away for safekeeping. The Internet, though, has today created new ways, and hence new moral imperatives, to share more widely scans and photographs of such art objects. It would be good if the owner posting one would also use flicker analysis to identify whether it is a similar or variant form to any other, or rather a new state in a known series.

\section{Acknowledgements}

Deep thanks to Jared Bendis (Creative New Media Officer for Digital Learning and Scholarship at Case Western Reserve University), for digital magic. Early on, Erik Schmittgen of the John Carroll University Center for Digital Media produced my first working flicker display. And thanks also for her encouragement and writing advice to Professor Suzanne Ferguson of the CWRU English department.

${ }^{4}$ Such paintings by Rembrandt include his early "The Rich Farmer", "The Descent from the Cross" (Rembrandt workshop), "The Adoration of the Shepherds", and "The Apostle Peter Denying Christ" (Bredius 420, 551, 574, and 594; Tümpel, 1993: pp. 29, 151, 247, and 352). Rembrandt print scenes similarly lit by a single lantern include "The Rest on the Flight", "The Flight into Egypt", "The Adoration of the Shepherds", and probably "The Entombment" (White, 1969, plates 52-54, 76-81, 82-85, and 102-105). 


\section{Conflicts of Interest}

The author declares no conflicts of interest regarding the publication of this paper.

\section{References}

Buser, P., \& Imbert, M. (1992). Vision (Trans. R. H. Kay, pp. 98 ff., Original Appeared in France in 1987). Cambridge, MA: MIT Press.

Davson, H. (1990). Physiology of the Eye (5th ed., pp. 219-220, 264-278). New York: Pergamon Press. https://doi.org/10.1007/978-1-349-09997-9

Hinman, C. (1955). Mechanized Collation at the Houghton Library. Harvard Library Bulletin, 9, 132-134.

Hinman, C. (1963). The Printing and Proof-Reading of the First Folio of Shakespeare (Two Volumes). Oxford: Oxford University Press.

Netherlands (1953). In Compton's Pictured Encyclopedia (Vol. 10, p. 116). Chicago: F. E. Compton.

Tümpel, C. (1993). Rembrandt: All Paintings in Colour (Translation of 1986 German Edition). Antwerp: Fonds Mercator.

White, C. (1969). Rembrandt as an Etcher: A Study of the Artist at Work (Plates Volume). University Park: Pennsylvania State University Press. 